\title{
Residuos de tetraciclina y quinolonas en peces silvestres en una zona costera donde se desarrolla la acuicultura del salmón en Chile
}

\author{
Antonia Fortt Z., Felipe Cabello C. y Alejandro Buschmann R.
}

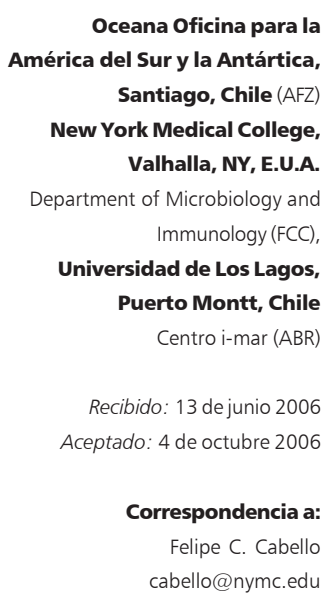

\section{Introducción}

$\mathrm{E}$ 1 desarrollo de la acuicultura en Chile ha estado caracterizado por un uso importante de antimicrobianos en esta industria productora de alimentos ${ }^{1}$. Por ejemplo, el uso de flumequina, una fluoroquinolona usada exclusivamente en la acuicultura, aumentó de aproximadamente 30 toneladas, a cerca de 100 toneladas entre los años 1998 y $2002^{1,2}$. Este aumento coincide con un crecimiento en la producción de salmón de 258.000 toneladas el año 1998 a 494.000 toneladas el año $2002^{1}$, llegando Chile a situarse como el segundo productor mundial de salmón cultivado, después de Noruega ${ }^{3}$. La existencia de enfermedades bacterianas con implicaciones económicas para la industria acuícola, ha demandado en esta industria el uso importante de antimicrobianos en la prevención y tratamiento de estas enfermedades ${ }^{1,4,5}$. Como ha sido demostrado en otros países, este uso excesivo de antimicrobianos en acuicultura tiene implicaciones negativas para la salud humana y ani$\mathrm{mal}^{4,6-8} \mathrm{y}$ para el medio ambiente ${ }^{2,9-11}$. En Noruega para minimizar los efectos deletéreos de este uso excesivo de antimicrobianos, se eliminó, totalmente, su uso profiláctico en acuicultura ${ }^{7,8,12}$, eliminándose también el uso de aquellos antimicrobianos de relevancia para la salud humana, como las quinolonas ${ }^{7,8,12}$. Además, estas regulaciones controlaron el uso terapéutico de los antimicrobianos en acuicultura de manera drástica, a través de la vigilancia epidemiológica mantenida por las instituciones gubernamentales de salud pública, animal y humana ${ }^{7,8,12}$.

En Chile, como en otras partes del mundo, los recintos acuícolas y sus jaulas están rodeados de diversos ambientes acuáticos donde habitan y se realiza la pesca artesanal de diferentes especies de mariscos y peces silvestres para el consumo humano9. Algunas de estas especies se nutren del alimento no consumido por los peces cultivados y de las heces de estos mis$\operatorname{mos}^{12-14}$, las cuales se acumulan debajo de las jaulas ${ }^{3,12-14}$. De esta forma, diferentes especies de peces silvestres pueden ser expuestos de manera involuntaria a los antimicrobianos potencialmente presentes en el alimento no ingerido y en las heces y por esta razón, su carne puede estar contaminada con residuos de antimicrobianos, teniendo entonces éstos la posibilidad de pasar al tracto digestivo de sus consumidores humanos ${ }^{6,11,13}$. Por los potenciales problemas de salud humana y animal que la presencia de residuos de antimicrobianos en la carne de peces silvestres puede provocar y porque este fenómeno ha sido frecuentemente descrito ${ }^{6,11}$, decidimos investigar en forma preli- 
minar si en Chile, peces silvestres de consumo humano que viven en el entorno de los recintos acuícolas, presentan en su carne cantidades detectables de antimicrobianos y antiparasitarios. Investigamos la presencia de oxitetraciclina y de las quinolonas ácido oxolónico y flumequina porque estos son los antimicrobianos más usados por la industria acuícola en Chile $e^{1,2,5}$.

\section{Materiales y Métodos}

Recolección de la muestra. Durante el mes de noviembre del año 2005 se pescaron, en la localidad de

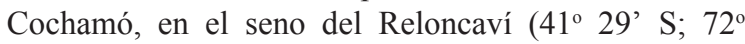
$\left.19^{\prime} \mathrm{W}\right), 60 \mathrm{Km}$ al sur de Puerto Montt, X Región, alrededor de un recinto acuícola que cultiva salmón del Atlántico (Oncorhynchus kisutch), trece individuos de especies de vida libre en el lugar (Figura 1A). La muestra incluyó cinco róbalos (Eleginops maclovinus), cinco cabrillas (Sebastes capensis) (Figura 1B) y tres truchas arco iris (Oncorhynchus mykiss) (Tabla 1). La pesca se efectuó a 30 metros de las jaulas de cultivo con anzuelos de $2 \mathrm{~cm}$, usando como carnada tabletas de alimento para salmón sin antimicrobianos. Los peces fueron sacrificados inmediatamente a bordo de la embarcación; fueron medidos con una regla $( \pm 1 \mathrm{~mm})$ y el contenido estomacal fue determinado, verificando la presencia de tabletas de alimento para salmón (Figura 1C). Inmediatamente después de estos procedimientos, los peces fueron conservados en hielo y llevados al laboratorio de análisis SGS Aquatic Health, en Puerto Varas, en un plazo de seis horas, con el propósito de investigar la presencia de residuos de antimicrobianos en sus tejidos.

Análisis de antimicrobianos residuales. De los 13 peces descritos en la sección anterior se obtuvo muestras de tejido muscular que se analizaron para detectar en ellas la presencia de oxitetraciclina, emamectina, ivermectina, ácido oxolínico y flumequina, los cuales son algunos de los antimicrobianos y antiparasitarios más usados en acuicultura en Chile. Las técnicas empleadas para detectar estos antimicrobianos y antiparasitarios están basadas en la extracción de muestras de
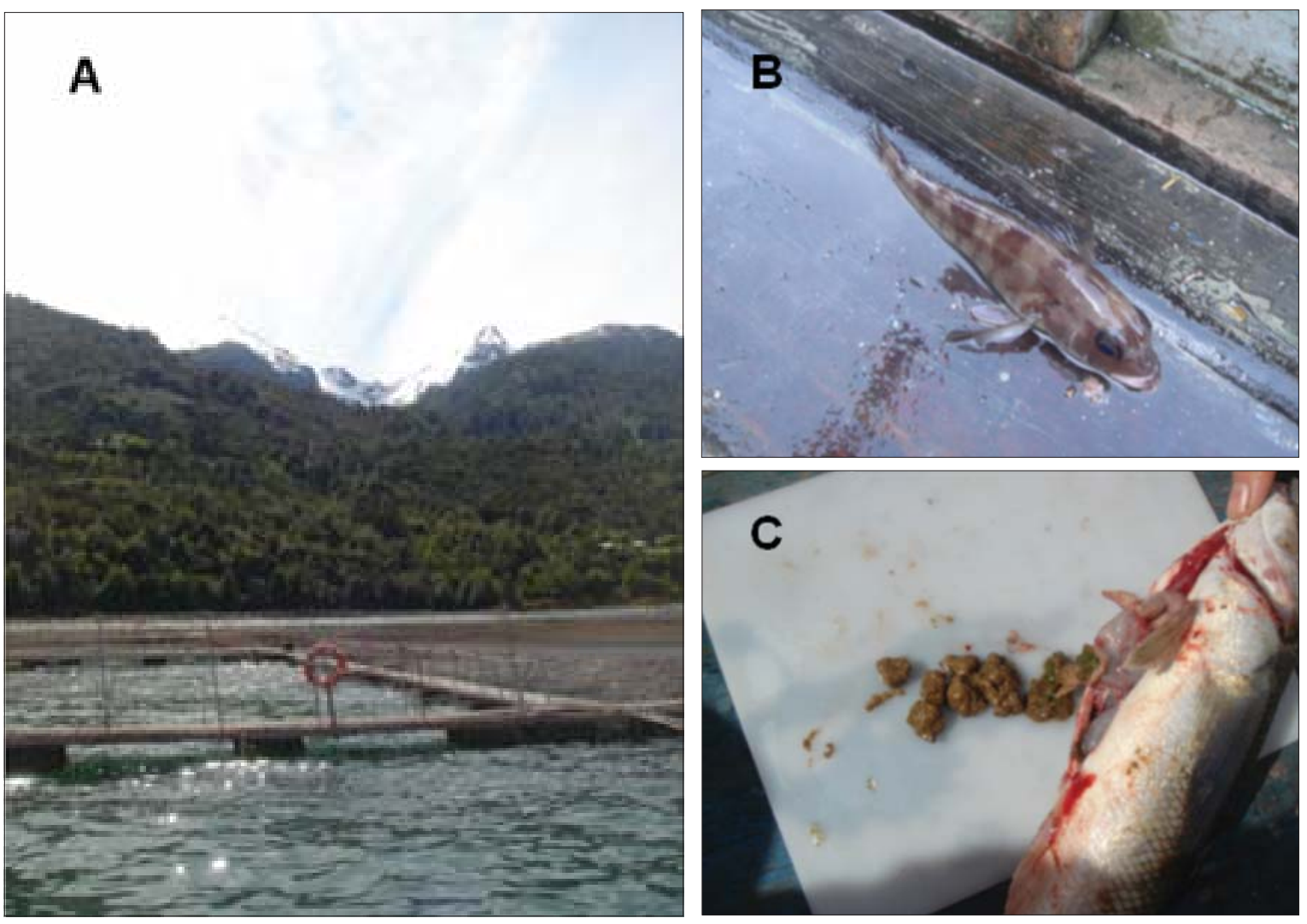

Figura 1. Fotografías muestran: A. Sitio cercano a Cochamó en las inmediaciones de las balsas jaula donde se realizó la pesca de peces nativos para este estudio. B. Cabrilla recién capturada. C. Contenido estomacal de un róbalo con tabletas de alimento para salmón. 
Tabla 1. Presencia de alimento en estómago y rango de concentraciones

de antimicrobianos (ppb) en filete de peces muestreados en un sitio cercano a jaulas de cultivo de salmones en, Cochamó, Estuario de Reloncaví, $\mathrm{X}$ Región, Chile

$\begin{array}{llccc}\text { Especie } & \mathbf{n} & \begin{array}{c}\text { Pellet } \\ \text { en estómago }\end{array} & \begin{array}{c}\text { Oxitetraciclina } \\ (\mathbf{p p b})\end{array} & \begin{array}{c}\text { Quinolonas* } \\ \text { (ppb) }\end{array} \\ \text { Cabrilla } & 1 & \text { Sí } & \text { ND } & \text { ND } \\ \text { (Sebastes capensis) } & 2 & \text { No } & \text { ND } & \text { ND } \\ & 3 & \text { No } & \text { ND } & \text { ND } \\ & 4 & \text { Sí } & \text { ND } & 2 \\ & 5 & \text { No } & 87 & \text { ND } \\ \text { Róbalo } & 1 & \text { No } & \text { ND } & \text { ND } \\ \text { (Eleginops maclovinus) } & 2 & \text { Sí } & \text { ND } & \text { ND } \\ & 3 & \text { Sí } & \text { ND } & 4 \\ & 4 & \text { Sí } & \text { ND } & \text { ND } \\ & 5 & \text { Sí } & \text { ND } & \text { ND } \\ \text { Trucha arco iris } & 1 & \text { Sí } & \text { ND } & \text { T } \\ \text { (Oncorhynchus mykiss) } & 2 & \text { Sí } & \text { ND } & \text { ND } \\ & 3 & \text { Sí } & \text { ND } & \text { ND }\end{array}$

ND: No Detectado, oxitetraciclina $<30 \mathrm{ppb}$ y quinolonas $<1 \mathrm{ppb}$ ) *: Cabrilla (n: 4) y róbalo ( $n$ : 3 ) contienen ácido oxolínico; trucha arco iris $(n: 1)$ contiene flumequina; T: Trazas entre 1 y 2 ppb.
En ninguna de las muestras de tejido se detectó la presencia de los antiparasitarios emamectina e ivermectina. La Tabla 1 indica que en la carne de una cabrilla que contenía tabletas de alimento para salmón en su estómago, se detectaron 2 partes por billón de la quinolona ácido oxolínico. Similarmente, en un róbalo que también tenía alimento para salmón en su estómago se hallaron 4 partes por billón de este mismo compuesto. Ochenta y siete partes por billón de oxitetraciclina fueron detectadas en otra cabrilla que no contenía tabletas de alimento para salmón en su intestino. Una trucha arco iris contenía trazas de flumequina.

\section{Discusión}

Los resultados de este estudio confirman que peces silvestres, que viven alrededor de los recintos de acuicultura y que son consumidos por humanos, ingieren alimento preparado para salmón; y que si este alimento está medicinado con antimicrobianos $u$ otros fármacos, éstos pasan a la carne de los peces y permanecen en ella en cantidades detectables ${ }^{6,11}$. Resultados similares han sido encontrados en otras regiones del mundo donde se practica la acuicultura del salmón de manera industrial ${ }^{16,11}$. Si bien es cierto que los niveles de tetraciclina y quinolonas detectados en peces silvestres en este estudio preliminar, son menores que los niveles máximos residuales tolerados por el Codex Alimentarium (200 ppb para tetraciclina y 500 ppb para flumequina $)^{17}$ y Sernapesca en nuestro país (100 ppb para tetraciclina y $600 \mathrm{ppb}$ para flumequina) ${ }^{18}$, ellos indican, claramente, que la fauna silvestre alrededor de los recintos de acuicultura, está siendo contaminada con antimicrobianos $\mathrm{s}^{6,11,12}$. Especialmente inquietante desde el punto de vista de salud pública, aparece la detección de ácido oxolínico en la carne de estos peces, antimicrobianos totalmente proscrito en la acuicultura en otros países por su eficacia en medicina humana ${ }^{7,8}$. Estos hallazgos indican que esta contaminación necesita ser monitoreada temporal y espacialmente por sus implicaciones para la salud humana y animal y por sus efectos medio ambientales, ya que probablemente en varias oportunidades, residuos de antimicrobianos en estos peces pueden superar los niveles máximos permitidos por organismos reguladores nacionales e internacionales ${ }^{7,8,17,18}$. La ingestión de carne de pez contaminada con antimicrobianos tiene el potencial de alterar la microbiota residente del tracto digestivo humano, favoreciendo la infección por patógenos como Salmonella ${ }^{2,5}$, puede seleccionar a bacterias resistentes a los antimicrobianos en esta microbiota residente $2,5 \mathrm{y}$, por último, puede provocar fenómenos tóxicos y alérgicos difíciles de diagnosti- 
car por la falta del antecedente de la ingestión de antimicrobianos ${ }^{2,5}$. Estos antimicrobianos residuales pueden también seleccionar bacterias resistentes a ellos en la microbiota residente de peces silvestres, incluyendo patógenos, los cuales, potencialmente, infectarán a los peces criados en los recintos de acuicultura y afectarán la salud de los peces en culti$\mathrm{vo}^{2,12,19}$.

La presencia de antimicrobianos residuales, incluyendo tetraciclinas y ácido oxolínico en partidas de salmón de exportación y probablemente también presente en partidas de salmón consumido en el país, ha sido otro efecto deletéreo con proyecciones económicas en la industria acuícola en Chile ${ }^{20}$. Este uso excesivo de antimicrobianos tiene también el potencial de dañar la salud económica de la industria por el aumento de la resistencia en bacterias patógenas para peces, por la aparición de nuevos patógenos para peces en cultivo y por la pérdida de prestigio producida por la presencia de antimicrobianos residuales en la carne de exportación de peces cultivados ${ }^{20}$. Los planes de crecimiento de la industria acuícola nacional sugieren que la presencia de estos problemas sanitarios se agudizarán en el país, a menos que entre la industria, los consumidores y las entidades gubernamentales encargadas de proteger la salud humana y animal, acuerden medidas que regulen el excesivo uso de antimicrobianos en esta industria ${ }^{2,9,10}$.

La política ambiental de la acuicultura en Chile correspondiente al Reglamento Ambiental para la Acuicultura (RAMA), no contempla la regulación del uso de antimicrobianos, ya que se limita a establecer primariamente los efectos localizados de esta actividad sobre los fondos marinos ${ }^{21}$. Sin embargo, estos resultados preliminares sugieren que los efectos de la acuicultura se proyectan más allá del ámbito geográfico de ésta, como lo demuestra la dispersión de antimicrobianos residuales detectadas en peces silvestres y podrían incluso alcanzar a la población humana, si estos peces con antimicrobianos residuales son ingeridos por ella ${ }^{21}$. En consecuencia, nuestros hallazgos implican que se deberían establecer aproximaciones ecosistémicas para controlar los efectos ambientales y las consecuencias para la salud humana y animal que esta actividad tiene ${ }^{21-23}$.

\section{Resumen}

La presencia de antibacterianos y antiparasitarios residuales fue investigada en muestras de carne de peces silvestres de consumo humano pescados alrededor de un recinto de acuicultura en Cochamó (41 ${ }^{\circ}$ 29' S; 72 19'W), X Región, Chile. Esta investigación demostró que peces silvestres, incluyendo róbalo (Scorpaena hystrio), cabrilla (Elginops maclovinus) y truchas de vida libre (Oncorhynchus mykiss), ingieren alimento artificial para salmón y que la carne de algunos ejemplares de estos peces contienen tetracicilina y quinolona en cantidades detectables. Estos resultados sugieren que el uso de antibacterianos en la acuicultura del salmón, como ha sido demostrado en otros países, tiene efectos ambientales que se proyectan más allá de los recintos de acuicultura. Se indica que dada la relevancia de estos hallazgos para la salud humana y animal, el ambiente requerirá de estudios más amplios y detallados para implementar futuras regulaciones del uso de antibacterianos en acuicultura.

\section{Agradecimientos}

Este estudio fue apoyado y financiado por la organización no gubernamental Oceana para la América del Sur y la Antártica y contó con la ayuda logística de Remigio Gutiérrez, Diego Valderrama y Luis Henríquez. Felipe C. Cabello agradece el otorgamiento de una beca USA-Canadá de la Fundación John Simon Guggenheim y a las Sras. H. Harrison y Betty Barria en la preparación del manuscrito.

\section{Referencias}

1.- Bravo S, Dolz H, Silva M T, Lagos C, Millanao A, Urbina M. Informe Final. Diagnóstico del uso de fármacos y otros productos químicos en la acuicultura. 2005. Universidad Austral de Chile. Facultad de Pesquerías y Oceanografía, Instituto de Acuicultura. Casilla 1327. Puerto Montt, Chile. Proyecto No 2003; 28.

2.- Cabello F C. Heavy use of prophylactic antibiotics in aquaculture: a growing problem for human and animal health and for the environment. Environ Microbiol 2006; 8: 1137-44

3. - Soto D, Norambuena F. Evaluation of salmon farming effects on marine systems in the inner seas of southern Chile: a largescale mensurative experiment. J Appl Ichthyol 2004; 20: 493-501.

4.- Cabello F C. Antibiotics and aquaculture in Chile: Implications for human and animal health. Rev Méd Chile 2004; 132: 1001-6.

5.- Cabello F C. Antibiotics and aquaculture. An analysis of their potential impact upon the environment, human and animal health in Chile. Fundación Terram. (http://www. terram.cl/docs/App17_Antibiotics_y_ Acuicultura.pdf. (Accedido mayo 2006). Análisis de Políticas Públicas 2003; 17: 1-16.

6.- Bjorlund H, Bondestam J, Bylund G. Residues of oxytetracycline in wild fish and sediments from fish farms. Aquaculture 1990; 86: 359-67.

7.- Wolff M. Uso y abuso de antibióticos. Momento de su evaluación, más allá del ser 
humano. Rev Méd Chile 2004; 132: 909-11.

8.- Grave K, Lingaas E, Bangen M, Rønning M. Surveillance of the overall consumption of antibacterial drugs in humans, domestic animals and farmed fish in Norway in 1992 and 1996. J Antimicrob Chemother 1999; 43: 243-52.

9.- Buschmann A H, Riquelme V A, HernándezGonzález M C, Varela D, Jiménez J E, Henríquez L A, et al. A review of the impacts of salmon farming on marine coastal ecosystems in the southeast Pacific. ICES J Marine Sci 2006a; 63: 1338-45.

10.- Hektoen H, Berge J A, Hormazabal V, Yndestad M. Persistence of antibacterial agents in marine sediments. Aquaculture 1995; 133: 175-84.

11.- Samuelsen O B, Lunestad B T, Husevag B, Holleland T, Ervik A. Residues of oxolinic acid in wild fauna following medication in fish farms. Dis Aquat Org 1992; 12: 111-9.

12.- Sørum H. Antimicrobial drug resistance in fish pathogens. In Antimicrobial Resistance in Bacteria of Animal Origin. Aarestrup FM, ed. Washington, DC: ASM Press 2006; p 213-38.

13.- Coyne R, Hiney M, Smith P. Transient presence of oxytetracycline in blue mussels (Mytilus edulis) following its therapeutic use at a marine Atlantic salmon farm. Aquaculture. 1997; 149: 175-81.

14.- Kerry J, Coyne R, Gilroy D, Hiney M, Smith P. Spatial distribution of oxytetracycline and elevated frequencies of oxytetracycline resistance in sediments beneath a marine salmon farm following oxytetracycline therapy. Aquaculture 1996; 145: 31-9.

15.- Reveurs T, Díaz R. Método de determinación de tetraciclinas en tejido por HPLCDiode - Array. Centro Nacional de Alimentación. Instituto de Salud Carlos III. Madrid. España. 1994.

16.- Degroodt J M, Wyhowski de Bukanski B W, Srebrnik S. Oxolinic acid and flumequine in fish tissues: Validation of an HPLC method; analysis of medicated fish and commercial fish samples. J Chromatogr 1994; 17: 85-94.

17.- Codex Alimentarius. 2006. URL. http:// www.codexalimentarius.net./mrsl/vetdrugs/ jsp/vetd_q-e.jsp. (Accedido mayo 2006).

18.- Servicio Nacional de Pesca. Requisitos generales para la certificación sanitaria de los productos pesqueros de exportación. Norma Técnica sección 1. 2005. Mayo. Santiago. Chile.

19.- Husevåg $\mathrm{B}$, Lunestad $\mathrm{B} \mathrm{T}$, Johannessen $\mathrm{PJ}$, Enger O, Samuelsen O B. Simultaneous occurrence of Vibrio salmonicida and antibiotic-resistant bacteria in sediments at abandoned aquaculture sites. J Fish Dis 1991; 14: 631-40.

20.- Ecoceanos. Detectan residuos de antibióticos en envío de salmón chileno a Estados Unidos. 2006. URL. http://www.ecoceanos. cl. (Accedido Mayo 2006).

21.- Buschmann A H, Riquelme V A, HernándezGonzález C, Henríquez L A. Chile. En The Role of Aquaculture in Integrated Coastal and Ocean Management: An Ecosystem Approach. 2006b. McVey J, Lee C-S y O'Bryen PJ, editors. The World Aquaculture Society, USA, Louisiana, Baton Rouge: En prensa.

22.- Hunter-Cevera J, Karl D, Buckley M. Marine microbial diversity: The key to earth's habitability. A report from The American Academy of Microbiology Colloquium held April 8-10, 2005, San Francisco, CA, USA: Marine Microbial Diversity. Collier RJ. et al., editors. Washington, DC: American Academy of Microbiology. 2005; p 1-22.

23.- Miranda C D, Zemelman R. Antimicrobial multiresistance in bacteria isolated from freshwater Chilean salmon farms. Sci Total Environ 2002; 293: 207-18. 